\title{
Analysis and Prevention of Voice Morbidity in Thyroidectomy Patients: A Prospective Study
}

Prabu Velayutham ${ }^{1}$, Sathiyan Murugaiyan ${ }^{2}$

\begin{abstract}
Background: Preservation of voice is an important concern for patients undergoing thyroidectomy. The objective of our study was early identification of the voice-related problems in postthyroidectomy patients and starting voice therapy as early as possible, in order to prevent faulty voice production techniques in them.

Materials and methods: One hundred and eighteen patients who underwent thyroidectomy in our study period were included for study. Voice evaluation was done preoperatively and postoperatively with videolaryngoscopy (VLS), maximum phonation duration (MPD), and fundamental frequency of voice (Fo). Voice therapy was initiated in patients who had voice disorders.

Results: Thirty-three patients in early postoperative period had voice disorders. Among these 33 patients, four patients had recurrent laryngeal nerve (RLN) paresis, 22 patients had external branch of superior laryngeal nerve (EBSLN) paresis, and 7 patients had normal vocal fold mobility. Four patients had voice changes in the late postoperative period. Voice rehabilitation therapy was started in these 33 patients. All the patients recovered well with voice therapy and without surgical intervention.
\end{abstract}

Conclusion: Early identification of voice disorders and initiation of voice rehabilitation therapy will considerably reduce the voice morbidity in thyroidectomy patients.

Keywords: Recurrent laryngeal nerve, Thyroidectomy, Vocal fold, Voice disorders, Voice rehabilitation.

Otorhinolaryngology Clinics: An International Journal (2019): 10.5005/jp-journals-10003-1309

\section{INTRODUCTION}

Altered voice is a common problem after thyroid surgery. Previous studies demonstrate that $25-90 \%$ of patients report abnormal voice within the first few weeks after operation and $11-15 \%$ of patients report persistent voice problems 3-6 months after thyroidectomy. ${ }^{1,2}$ Major laryngeal nerve injuries account for a large portion of this incidence and are well-established and feared complications of thyroidectomy. ${ }^{3,4}$ But many patients suffer long-term negative voice outcomes (NVOs) and have no evidence of laryngeal nerve injury. ${ }^{5}$ Various non-neurogenic mechanisms have been postulated to account for postthyroidectomy voice changes, including the effects of endotracheal intubation ${ }^{6}$ and other alterations in normal anatomy and mechanical factors. ${ }^{7}$

Our study was aimed at the ability to identify early changes in voice indicative of durable dysfunction (both neurogenic and non-neurogenic). This would facilitate early referral for comprehensive voice evaluation aimed to improve quality of life, prevent secondary injuries, and identify patients who might benefit from vocal fold augmentation..$^{8,9}$ All patients in this study were subjected to videolaryngoscopic examination, assessment of fundamental frequency of voice, and maximum phonation duration preoperatively and postoperatively. ${ }^{10-12}$ Patients with voice change were subjected to early voice therapy and the outcome was assessed.

\section{Material and Methods}

This study is a prospective study conducted in a tertiary care teaching hospital, from December 2011 to May 2013. Patients of both sexes of all age groups with preoperative normal vocal cord mobility undergoing thyroidectomy were included for study. Patients with vocal cord paralysis preoperatively and patients with

\begin{abstract}
1,2 Department of ENT, Sri Venkateshwara Medical College Hospital and Research Centre, Ariyur, Puducherry, India

Corresponding Author: Prabu Velayutham, Department of ENT, Sri Venkateshwara Medical College Hospital and Research Centre, Ariyur, Puducherry, India, Phone:+91 9787138601, e-mail:drvprabu@gmail.com How to cite this article: Velayutham P, Murugaiyan S. Analysis and Prevention of Voice Morbidity in Thyroidectomy Patients: A Prospective Study. Int J Otorhinolaryngol Clin 2019;11(2):45-48.
\end{abstract}

Source of support: Nil

Conflict of interest: None

a past history of neck surgeries were excluded from the study. One hundred and eighteen patients who fulfilled the inclusion criteria were enrolled in the study after getting the informed consent during the study period.

Preoperative voice assessment was done for all the study patients with videolaryngoscopy, analysis of maximum phonation duration (MPD), and fundamental frequency (Fo). Postoperatively, VLS, MPD and Fo were repeated at the second and sixth month in patients with voice change. Videolaryngoscopic examinations were done for all patients using an Atmos stroboscopic unit. Voice was recorded using a microphone, by asking the patient to say constant syllable and the fundamental frequency was evaluated. Maximum phonation duration was measured by asking the patient to take a deep breath and say a constant syllable.

Subjective voice change is assessed by GRBAS (Grade, Roughness, Breathiness, Asthenia, and Strain), an auditoryperceptual evaluation method for hoarseness. Voice therapy given by voice pathologists following eclectic approaches which include vocal hygiene, abdominal support/breath control, intrinsic

(c) The Author(s). 2019Open Access This article is distributed under the terms of the Creative Commons Attribution 4.0 International License (https://creativecommons. org/licenses/by-nc/4.0/), which permits unrestricted use, distribution, and non-commercial reproduction in any medium, provided you give appropriate credit to the original author(s) and the source, provide a link to the Creative Commons license, and indicate if changes were made. The Creative Commons Public Domain Dedication waiver (http://creativecommons.org/publicdomain/zero/1.0/) applies to the data made available in this article, unless otherwise stated. 
laryngeal muscle exercises, accent method, head and neck relaxation, and resonant voice/humming. Data regarding age, sex, final diagnosis, malignant nature of tumors, type of surgery, and percentage of EBSLN were collected. Distribution of the sample according to subjective voice change, cause of subjective voice change, and voice rehabilitation was also studied. VLS, Fo, MPD were compared at different intervals of time.

\section{Data Analysis}

The data were analyzed using the statistical software SPSS version 11.0. Wilcoxon matched-pairs signed rank test was used to analyze the video-strobo-laryngoscopic findings preoperatively and postoperatively. A $p$ value of $<0.05$ was considered significant. Fundamental frequency of voice and MPD were analyzed using paired $t$ test and Chi-squared test; a $p$ value of $<0.01$ was considered significant.

\section{Results}

The results are as follows after analysis of data (Tables 1 to 12).

Table 1: Percentage distribution of the sample according to age

\begin{tabular}{lll}
\hline Age & Number of patients & Percentage \\
\hline $20-29$ & 12 & 10.2 \\
$30-39$ & 31 & 26.3 \\
$40-49$ & 36 & 30.5 \\
$50-59$ & 29 & 24.6 \\
$\geq 60$ & 10 & 8.5 \\
Mean \pm SD & $43.7 \pm 10.7$ & \\
\hline
\end{tabular}

Maximum number of participants belongs to the age group 40-49 years

Average age of the participants was $43.7 \pm 10.7$ years

Table 2: Percentage distribution of the sample according to sex

\begin{tabular}{lll}
\hline Sex & Count & Percentage \\
\hline Male & 27 & 22.9 \\
Female & 91 & 77.1 \\
\hline
\end{tabular}

Majority of the participants were women: $77.1 \%$

Table 3: Percentage distribution of the sample according to final diagnosis

\begin{tabular}{lcc}
\hline Final diagnosis & Count & Percentage \\
\hline Colloid nodule & 2 & 1.7 \\
de Quervain thyroiditis & 1 & 0.8 \\
Follicular adenoma & 4 & 3.4 \\
Follicular carcinoma & 2 & 1.7 \\
Hashimoto's thyroiditis & 2 & 1.7 \\
Hürthle cell adenoma & 2 & 1.7 \\
Hürthle cell tumor & 1 & 0.8 \\
Hyperplastic nodule & 1 & 0.8 \\
Left colloid nodule & 3 & 2.5 \\
Left follicular adenoma & 1 & 0.8 \\
Lymphocytic thyroiditis & 2 & 1.7 \\
Multinodular goiter & 78 & 66.1 \\
Papillary carcinoma thyroid & 14 & 11.9 \\
Papillary microcarcinoma & 1 & 0.8 \\
Right colloid adenoma & 1 & 0.8 \\
Right follicular adenoma & 1 & 0.8 \\
Right Hürthle cell adenoma & 2 & 1.7 \\
\hline
\end{tabular}

Majority of thyroidectomies were done for multinodular goiter (66.1\%)
Table 4: Percentage distribution of the sample according to malignant or nonmalignant nature

\begin{tabular}{lcl}
\hline Final diagnosis & Count & Percent \\
\hline Malignant & 17 & 14.4 \\
Nonmalignant & 101 & 85.6 \\
\hline
\end{tabular}

Maximum number of thyroid pathology is nonmalignant, which is $85.6 \%$

Table 5: Percentage distribution of the sample according to surgery

\begin{tabular}{lcc}
\hline Surgery & Count & Percent \\
\hline Left hemithyroidectomy & 5 & 4.2 \\
Right hemithyroidectomy & 8 & 6.8 \\
Total thyroidectomy & 105 & 89.0 \\
\hline
\end{tabular}

Total thyroidectomy carried out was for $89 \%$ of patients, while hemithyroidectomy was for $11 \%$

Table 6: Percentage distribution of the sample according to course of external branch of superior laryngeal nerve

\begin{tabular}{lll}
\hline Course of EBSLN & No. of patients & Percentage \\
\hline Type I & 85 & 72 \\
Type IIA & 12 & 10 \\
Type IIB & 11 & 9.5 \\
Not identified & 10 & 8.5 \\
\hline In our study, the most common course of EBSLN is Cernea type I (72\%)
\end{tabular}

Table 7: Percentage distribution of the sample according to subjective voice change

\begin{tabular}{lll}
\hline Subjective voice change & Count & Percent \\
\hline Yes & 33 & 28.0 \\
No & 85 & 72.0 \\
\hline
\end{tabular}

Subjective voice change following thyroidectomy was observed in 33\% of patients

Table 8: Percentage distribution of the sample according to cause of subjective voice change

\begin{tabular}{lcc}
\hline $\begin{array}{l}\text { Causes of subjective } \\
\text { voice change }\end{array}$ & No. of patients & Percentage \\
\hline RLN palsy & 4 & 3.4 \\
EBSLN palsy & 22 & 18.6 \\
Normal vocal cords & 7 & 5.9 \\
\hline EBSLN palsy was observed in $18.6 \%$ of the patients and $4 \%$ had RLN palsy
\end{tabular}

Table 9: Percentage distribution of the sample according to voice rehabilitation

\begin{tabular}{lll}
\hline Voice rehabilitation & Count & Percent \\
\hline Started & 33 & 28.0 \\
Not done & 87 & 72.0 \\
\hline
\end{tabular}

Voice rehabilitation therapy started in all patients with voice change (28\%)

\section{Discussion}

Preservation of voice is an important concern for patients undergoing thyroid surgery. However, vocal and laryngeal symptoms appear to be common following thyroidectomy. ${ }^{13}$ The outcomes of injury to RLN and EBSLN are well known and preservation of these nerves is the major point in modern thyroid surgery. ${ }^{14}$ However, the etiology of postthyroidectomy voice 
Voice Morbidity in Thyroidectomy Patients

Table 10: Comparison of VLS at different intervals of time

\begin{tabular}{lllllc}
\hline VLS & Normal & Abnormal & Pair & Z\# & $p$ \\
\hline Preoperative (A) & $118(100)$ & $0(0)$ & - & - & - \\
$\begin{array}{l}\text { Postoperative 1-2 } \\
\text { weeks (B) }\end{array}$ & $92(78)$ & $26(22)$ & A vs B & $5.1^{*}$ & 0.000 \\
Follow-up, 2 months (C) & $111(94.1)$ & $7(5.9)$ & A vs C & $2.65^{*}$ & 0.008 \\
Follow-up, 6 months (D) & $114(96.6)$ & $4(3.4)$ & A vs D & $2^{* *}$ & 0.046 \\
\hline
\end{tabular}

*Significant at 0.01 level; ** significant at 0.05 level. VLS findings shows $3.4 \%$ of abnormal findings after 6 months of surgery, compared to $22 \%$ in the early postoperative period

Table 11: Comparison of fundamental frequency of voice at different intervals of time

\begin{tabular}{lllllc}
\hline FO & Mean & SD & Pair & Paired t & $p$ \\
\hline Preoperative (A) & 214.3 & 13.1 & - & - & - \\
$\begin{array}{l}\text { Postoperative 1-2 } \\
\text { weeks (B) }\end{array}$ & 207.1 & 14.8 & A vs B & $10.32^{*}$ & 0.000 \\
Follow-up, 2 months (C) & 210.5 & 13.6 & A vs C & $10.14^{*}$ & 0.000 \\
Follow-up, 6 months (D) & 211.9 & 13.1 & A vs D & $10.44^{*}$ & 0.000 \\
\hline
\end{tabular}

Mean Fo in the late postoperative period (after 6 months) was higher than that of the early postoperative period, not reaching the preoperative value. *Significant at 0.01 levels

Table 12: Comparison of maximum phonation duration at different intervals of time

\begin{tabular}{lllllc}
\hline MPD & Mean & SD & Pair & Paired t & $p$ \\
\hline Preoperative (A) & 16.2 & 2.5 & - & - & - \\
$\begin{array}{l}\text { Postoperative 1-2 } \\
\text { weeks (B) }\end{array}$ & 15.6 & 2.6 & A vs B & $4.88^{*}$ & 0.000 \\
Follow-up, 2 months (C) & 15.7 & 2.5 & & & \\
Follow-up, 6 months (D) & 15.9 & 2.4 & A vs C & $4.75^{*}$ & 0.000 \\
\hline
\end{tabular}

Mean MPD observed in our study preoperatively is 16.2 seconds and is 15.9 seconds after 6 months. ${ }^{*}$ Significant at 0.01 level

disturbances for patients with preserved nerve function has not been widely studied. ${ }^{15}$ The objective of our study was early identification of the voice related problems in postthyroidectomy patients and starting voice rehabilitation as early as possible, in order to prevent faulty voice production techniques in them. ${ }^{16,17}$

Out of 118 patients, 13 patients who underwent hemithyroidectomies had no voice changes. Thirty-three of the 105 patients (31.43\%) underwent total thyroidectomy and had subjective voice change in the early postoperative period. Only 4 patients (3.4\%) out of 105 underwent total thyroidectomy and had voice change after 6 months. In all patients, recurrent laryngeal nerve (RLN) was identified and was well preserved. In spite of the proper preservation, 4 patients (3.3\%) had RLN palsy postoperatively. Patients with postoperative videolaryngoscopic (VLS) features like posterior glottic rotation, bowing of vocal folds, asymmetrical mucosal folds vibration were considered as EBSLN palsy. ${ }^{18}$ Twenty-two patients had EBSLN palsy. Seven patients had voice change without any obvious abnormality in VLS. Their fundamental frequency increased after two months. Voice change in these patients may be due to forceful retraction, the application of cautery near cricothyroid muscle. $^{19}$

The most common course of EBSLN observed in our study is type I which was $72 \%$, followed by IIA in $10 \%$ and IIB in $9.5 \%$ of patients. EBSLN could not be identified in $8.5 \%$ of patients. It was observed that patients with type IIB course of nerve are more prone for injury. Hence, postoperative vocal cord examination is advisable for patients with type IIB course and in patients for whom EBSLN is not identified. ${ }^{20}$

The preoperative video-strobo-laryngoscopic examination of vocal cords of all patients was normal. Early postoperative period shows abnormality in 26 patients which includes complete immobility of the vocal cords, restricted vocal cord mobility, anterior glottis rotation, bowing of vocal folds, and absent or asymmetrical mucosal folds vibration. Early postoperative videolaryngoscopic findings are statistically significant as $p$ value is less than 0.05 . After postoperative initiation of voice rehabilitation therapy, VLS examination after 2 months showed abnormal findings in 7 patients. Late postoperative evaluation after 6 months showed abnormal findings in 4 patients, including restricted vocal mobility of vocal cord which was completely immobile previously in 2 patients and minimal bowing of vocal cord in 2 patients.

The mean fundamental frequency (Fo) of voice was $214.3 \mathrm{~Hz}$ preoperatively. The preoperative value of each patient was considered to be their normal value. Early postoperative mean Fo was $207.1 \mathrm{~Hz}$. Mean Fo at the 2-month postoperative period was $210.5 \mathrm{~Hz}$. The late postoperative mean Fo was $211.9 \mathrm{~Hz}$. The value was more than that of the early postoperative mean Fo but did not equal the preoperative value. The improvement was statistically significant as $p<0.01$.

Maximum phonation duration was 16.2 seconds preoperatively. Early postoperative value was 15.6 seconds. Late postoperative values were 15.7 and 15.9 seconds at 2-month and 6-month periods, 
respectively. This change was statistically significant as the $p$ value was less than 0.001 . At 6 months, only 4 patients had subjective voice change, compared to 33 in early postoperative period. The changes in fundamental frequency and maximum phonation duration compared to preoperative period were statistically significant $(p<$ 0.01). None of our patients was in need of vocal fold augmentation therapy. This study shows there was improvement in subjective voice and fundamental frequency and maximum phonation duration of the patients with voice therapy.

\section{Conclusion}

Voice change in early postoperative period after thyroidectomy is a common problem. Early identification of the problem and initiation of voice rehabilitation therapy will considerably reduce the voice morbidity in thyroidectomy patients.

\section{References}

1. Debruyne F, Ostyn F, Delaere P, et al. Acoustic analysis of the speaking voice after thyroidectomy. J Voice 1997;11:479-482. DOI: 10.1016/ S0892-1997(97)80046-X.

2. De Pedro Netto I, Fae A, Vartanian JG, et al. Voice and vocal selfassessment after thyroidectomy. Head \& Neck 2006;28:1106-1114. DOI: 10.1002/hed.20480.

3. Roy AD, Gardiner RH, Niblock WM. Thyroidectomy and the recurrent laryngeal nerve. Lancet 1996;270:988-990.

4. Cernea C, Ferraz A, Fulani J, et al. Identification of the external branch of the superior laryngeal nerve during thyroidectomy. Am J Surg 1992;164:634-638. DOI: 10.1016/S0002-9610(05)80723-8.

5. Pereira JA, Girvent M, Sancho JJ, et al. Prevalence of long-term upper aero-digestive symptoms after uncomplicated bilateral thyroidectomy. Surgery 2003;133:318-322. DOI: 10.1067/msy.2003.58.

6. Kark $A E$, Kissin MW, Auerbach $R$, et al. Voice changes after thyroidectomy: role of the external laryngeal nerve. Br Med J 1984;289:1412-1415. DOI: 10.1136/bmj.289.6456.1412.

7. Henry LR, Solomon NP, Howard R, et al. The functional impact on voice of sternothyroid muscle division during thyroidectomy.
Ann Surg Oncol 2008;15:2027-2033. DOI: 10.1245/s10434-0089936-8.

8. Chandrasekhar S, Randolph G, Seidman M, et al. Clinical Practice Guideline: Improving Voice Outcomes after Thyroid Surgery. Otolaryngol Head Neck Surg 2013;148(6):S1-S37. DOI: 10.1177/0194599813487301.

9. Sinagra DL, Montesinos MR, Tacchi VA, et al. Voice changes afterhyroidectomy without recurrent larnygeal nerve injury. J Am Coll Surg 2004;199:556-560. DOI: 10.1016/j.jamcollsurg.2004. 06.020 .

10. Casiano RR, Vijaykumar Z, Lundy DS. Efficacy of videostroboscopy in the diagnosis of voice disorders. Otolaryngol Head Neck Surg 1992;107:95-100. DOI: 10.1177/019459989210700115.

11. Kocak S, Aydintug S, Ozbas S, et al. Evaluation of vocal cord function after thyroid surgery. Eur J Surg 1999;165:183-186. DOI: 10.1080/110241599750007018.

12. Sataloff RT, Spiegel JR, Hawkshaw MJ. Strobovideolaryngoscopy: Results and clinical value. Ann Otol Rhinol Laryngol 1991;100:725-727. DOI: $10.1177 / 000348949110000907$.

13. Songun I, Kievit J, von de Velde $\mathrm{CJH}$. Complications of thyroidsurgery. In: Clark OH, Duh QY. ed. Textbook of EndocrineSurgery, 1st ed. Philadelphia, PA: Saunders; 1997. p. 167.

14. Rueger R. Benign disease of the thyroid gland and vocal cord paralysis. Laryngoscope 1974;84:897-907. DOI: 10.1288/00005537-19740600000002.

15. Bastian RW, Levine LA. Visual methods for the office. Diagnosis of voice disorders. Ear Nose Throat J 1988;67:363-379.

16. Kreiman Jody, Gerratt BR. Comparing two methods for reducing variability in voice quality measurements. J Speech Lang Hear Res 2010;54(3):803-812. DOI: 10.1044/1092-4388(2010/10-0083).

17. Scherer KR. Expression or emotion in voice and music. J Voice 1995;9:235-248. DOI: 10.1016/S0892-1997(05)80231-0.

18. Teitelbaum B, Wenig B. Superior laryngeal nerve injury from thyroid surgery. Head and Neck 1995;17:36-40. DOI: 10.1002/hed.2880170108.

19. Kumrow $D$, Dahlen R. Thyroidectomy: Understanding the potential for complications. Medsurg Nurs 2002;11(5):228-235.

20. Sercarz JA, Berke GS, Ming Y, et al. Videostroboscopy of human vocal fold paralysis. Ann Otol Rhinol Laryngol 1992;101:567-577. DOI: $10.1177 / 000348949210100705$. 